\title{
PLATELET DISTRIBUTION WIDTH VALUE AS A DIAGNOSTIC AND PROGNOSTIC MARKER IN ACUTE CORONARY SYNDROME
}

\author{
Rahmi Rifany Latif, Liong Boy Kurniawan, Darmawati Rauf
}

Department of Clinical Pathology, Faculty of Medicine, Hasanuddin University/ Dr.Wahidin Sudirohusodo Hospital, Makassar, Indonesia. E-mail: rahmilatif@ymail.com

\begin{abstract}
An acute coronary syndrome is a form of clinical manifestation of coronary heart disease with atherosclerosis, and thrombosis processes. Platelets play an essential role in thrombosis. High PDW shows a variation of the morphology, and size of a platelet. This was a retrospective cross-sectional study comparing PDW, length of stay, and patient outcome in STEMI, NSTEMI, UAP, and control patients at the Dr.Wahidin Sudirohusodo Hospital Makassar during the period of January 2014 - December 2015. Data were analyzed using statistical software. One hundred, and seventy-two ACS patients were included; 65 patients had UAP, 48 patients had STEMI and 59 patients had NSTEMI. Sixty normal patients were included as a control. KruskalWallis test showed a statistical difference in PDW between patients with STEMI, NSTEMI, UAP, and control $(p=0.000)$. Post hoc test showed a significant difference between ACS, and control, STEMI, and control $(p=0.000), N S T E M I$ and control $(p=0.000), U A P$, and control $(p=0.000)$, but there no significant difference between STEMI, and NSTEMI ( $p=0.320)$, STEMI, and UAP $(p=0.980)$, NSTEMI and UAP $(p=0.435)$. There was no significant difference in PDW between patients who survived, and died $(p=0.298)$, and also patients with a length of stay of $\leq 7$ days, and $>7$ days $(p=0.293)$. Platelet distribution width was higher in ACS patients compared with control patients, but could not be used to predict the outcome, and length of stay of patients with ACS. It is advisable to do further research with a large sample size to avoid bias.
\end{abstract}

Keyword: Platelet distribution width, acute coronary syndrome

\section{INTRODUCTION}

An Acute Coronary Syndrome (ACS) is a condition that involves chest discomfort or other symptoms caused by lack of oxygen to the heart muscle (myocardium) due to a disturbance in the coronary artery. An Acute coronary syndrome is divided into three types, namely ST-Segment Elevation Myocardial Infarction (STEMI), Non-ST-Segment Elevation Myocardial Infarction (NSTEMI), and Unstable Angina Pectoris (UAP). Acute coronary syndrome, according to a report of WHO in 2008, was the leading factor causing death in developing countries with a mortality rate of 5.27 million (13.7\%), and also ranked third regarding a death-risk factor in low-income countries with a mortality rate of 0.57 million $(7.8 \%) .{ }^{1,2}$

Acute coronary syndrome, moreover, is one of the clinical manifestations of coronary heart disease, considered as a major result of the process of atherosclerosis, and thrombosis. Progressive platelet activation also leads to platelet morphological changes involving spherical transformation, and pseudopod formation that will cause platelet size to vary, generating platelet distribution width value. Platelet Distribution Width (PDW) is a quantitative measure of the size, and shape variations of platelets. ${ }^{3-8}$ Increased platelet consumption in atherosclerotic plaques then leads to an increase in the release of young platelets from bone marrow. Younger platelets have a larger size that is more adhesive and have a greater aggregation tendency due to the secretion of $A 2$ thromboxane, releasing more serotonin, and $\beta$-thromboglobulin as well as expressing more Ib and Ilb / IIla glycoproteins. atherosclerotic plaques then leads to an increase in the release of young platelets from bone marrow. Younger platelets have a larger size that is more adhesive and have a greater aggregation tendency due to the secretion of $A 2$ thromboxane, releasing more 
serotonin, and $\beta$-thromboglobulin as well as expressing more $\mathrm{lb}$ and $\mathrm{Ilb} / \mathrm{IIla}$ glycoproteins.

Furthermore, PDW can also be used to measure the size and shape variations of platelets quantitatively. Similarly, platelet distribution width, according to a research conducted by Pervin et al., ${ }^{4}$ can be used as a predictor of early detection of an acute coronary syndrome. Other previous researches even have shown that PDW is significantly higher in patients with myocardial infarction when compared with the control ones..$^{4-9}$ It seems that the pathogenesis of ACS can easily be examined with PDW. As a result, this research aimed to analyze the difference of PDW values in ACS-STEMI, ACSNSTEMI, and ACS-UAP. This research also aimed to calculate PDW value related to the length of stay, and the output of ACS-STEMI, ACS-NSTEMI, and ACS-UAP.

\section{METHODS}

This research was a retrospective observational study. Data used in this research were collected from ACS patients treated at the Dr. Wahidin Sudirohusodo Hospital in Makassar from January 2014 to December 2015. Those ACS patients selected had been diagnosed with ACS-STEMI, ACSNSTEMI, and ACS-UAP by a cardiologist based on history as well as physical examination and investigation. Those ACS patients also had to have no history of coronary intervention or heart disease as well as incomplete medical record data.

Next, PDW values were calculated from results of routine blood tests using Sysmex XN-1000 and $A B X$ Pentra 80 hematology analyzer instruments. As a comparison, medical record data from patients declared healthy based on their history as well as physical and supporting examination results taken by candidates of Medical Education Program for Specialists were also used in this research as a control group.

Table 2. Analysis of differences in PDW values on ACS-
Afterward, the normality of the data was tested using Kolmogorov-Smirnov test. Results of the Kolmogorov-Smirnov test showed that the data were abnormally distributed, then presented in median form (lowest value-highest value). Next, PDW values of the STEMI, NSTEMI, and UAP groups were compared with PDW values of the control group using the KruskalWallis test. The data then were analyzed using a computer program with a $p$-value of $<0.05$.

\section{RESULTS AND DISCUSSION}

In total, there were 172 ACS patients whose medical record data were used in this research. There were sixty-five patients with STEMI, forty-eight patients with NSTEMI, and fifty-nine patients with UAP.

Table 1. Characteristics of acute coronary syndrome patients

\begin{tabular}{llcc}
\hline Variables & $\begin{array}{c}\text { Samples } \\
\mathbf{n}=172\end{array}$ & $\begin{array}{c}\text { Controls } \\
\mathbf{n}=60\end{array}$ \\
\hline Sex & Male & $128(74.4)$ & $22(46.66)$ \\
& Female & $44(25.6)$ & $38(63.33)$ \\
Age & $\leq 30$ years & $1(0.58)$ & $42(70)$ \\
& 31-40 years & $8(4.65)$ & 18(30) \\
& 41-50 years & $33(19.2)$ & \\
& $>60$ years & $130(75.5)$ & \\
& STEMI & $65(37.8)$ & \\
& NSTEMI & $48(27.9)$ & \\
& UAP & $59(34.3)$ & \\
Mortality & Survivied & $162(94.2)$ & \\
& Died & $10(5.8)$ &
\end{tabular}

Note: ACS: Acute Coronary Syndrome; UAP: Unstable Angina Pectoris; NSTEMI: Non-ST-Elevation Myocardial Infarction; STEMI: ST-Elevation Myocardial Infarction. The number of male ACS patients was also known to be higher than the female with the most age range between $47-69$ years, and the mean age of $11.25(28-95)$.

\begin{tabular}{cccccc}
\hline Variabels & $\begin{array}{c}\text { STEMI } \\
\text { Median }\end{array}$ & $\begin{array}{c}\text { NSTEMI } \\
\text { (min-max })\end{array}$ & $\begin{array}{c}\text { Median } \\
(\text { min-max })\end{array}$ & $\begin{array}{c}\text { UAP } \\
\text { Median } \\
(\text { min-max })\end{array}$ & $\begin{array}{c}\text { Control } \\
\text { Median } \\
(\min -\mathbf{m a x})\end{array}$ \\
\hline PDW & $11.0(7.3-19.3)$ & $11.25(7.7-22.3)$ & $11.3(8.7-17.3)$ & $10.05(7.8-12)$ & 0.000
\end{tabular}

Note: UAP: Unstable Angina Pectoris; NSTEMI: Non-ST-Elevation Myocard Infarction; STEMI: ST-Elevation Myocard Infarction; PDW: Platelet Distribution Width; *Kruskal-Wallis Test. 
Table 3. Analysis of differences in PDW value between the ACS patients, and the controls

\begin{tabular}{lclc}
\hline Variable & $\begin{array}{c}\text { Acute coronary syndrome } \\
\text { (STEMI + NSTEMI + UAP) } \\
\text { Median (min-max) }\end{array}$ & $\begin{array}{c}\text { Controls } \\
\text { median }\end{array}$ & $\begin{array}{c}\text { P- } \\
\text { value* }\end{array}$ \\
\hline PDW & $11.1(7.3-22.3)$ & 10.05 & 0.000 \\
& & $(7.8-12.0)$ & \\
\hline
\end{tabular}

Table 4. Differences of PDW based on the output of ACS patients

\begin{tabular}{lrcc}
\hline & N & Mean \pm SD & p-value* \\
\hline Survivied & 162 & $2.4(7.3-22.3)$ & 0.298 \\
Died & 10 & $1.4(9.9-14.0)$ & \\
\hline
\end{tabular}

* Mann-Whitney

Table 5. Differences of PDW values in ACS patients based on the length of stay

\begin{tabular}{lrcc}
\hline & $\mathbf{N}$ & Mean \pm SD & p-value * \\
\hline $\mathbf{S} 7$ days & 115 & $11.5 \pm 2.2$ & 0.293 \\
$>7$ days & 57 & $12.0 \pm 2.6$ & \\
\hline
\end{tabular}

* Mann-Whitney Test

Moreover, results of the Kruskal-Wallis test indicated that there was a significant difference in PDW between STEMI group, NSTEMI, group, UAP group, and the control one $(p=0.000)$. Next, Post-hoc test using Mann-Whitney analysis was, performed to analyze differences among them. Results of the MannWhitney test showed that there was no significant difference in PDW value between STEMI group, and NSTEMI group $(p=0.320)$, between STEMI group, and UAP group ( $p=0.980)$, as well as between NSTEMI group, and UAP group $(p=0.435)$. However, there were significant differences between STEMI group, and the control one $(p=0.000)$, between NSTEMI group, and the control one $(p=0.000)$, as well as between UAP group, and the controls $(p=0.000)$.

Furthermore, results of the Mann-Whitney analysis revealed that there was a significant difference in PWD values between the ACS patients, and the controls $(p=0.000)$.

The results of the Mann-Whitney test also showed that there was no significant difference in the output of ACS patients, between those who survived, and died ( $p=0.298)$.

In also, the results of the Mann-Whitney test indicated that there was no significant difference in the output of ACS patients, between those who survived, and died $(p=0.298)$. In also, the results of the
Mann-Whitney test indicated that there was no significant difference in the output of ACS patients, between the length of stays of $\leq 7$ days, and $>7$ days $(p=0.298)$. Besides, the results of this research also revealed that the number of ACS male patients was greater than the number of females, mostly at the age of 60 years i.e. 130 patients $(75.5 \%)$ as illustrated in Table 1. Similarly, Manchada et al., ${ }^{3}$ in Dheli reported that most patients suffering from ACS were male many as 110 patients (62.86\%) at the age of more than 50 years-old. ${ }^{3}$

In UAP, occlusion of the coronary artery is usually caused by an unstable plaque due to platelet aggregation. However, there is still no thrombus formation. Thrombus is found in atherosclerotic plaque of NSTEMI, and STEMI. Thus, it means that the greater the thrombus is, the more severe occlusion, and clinical symptoms are caused. The formation of an atherosclerotic plaque in the coronary arteries can cause partial blockage of the blood vessels, and also symptoms of chest pain. Unstable plaques will eventually lead to platelet activation, resulting in fibrin formation so that thrombus may aggravate occlusion in the coronary arteries, and eventually lead to myocardial infarction. In the late stage of the atherosclerosis process, enzymes released by platelets will degrade the matrix so that it can cause plaque rupture. Platelet adhesion, activation, and aggregation will trigger the formation of a thrombus that may lead to myocardial infarction. Progressive platelet activation even will lead to a change in platelet morphology including spherical transformation, and pseudopodia formation, which will cause platelet size to vary, generating PDW value in myocardial infarction patients higher than in controls. ${ }^{10-12}$

Similarly, the results of the Kruskal-Wallis test showed that there was a significant difference in PDW values between STEMI group, NSTEMI, group, UAP group, and the control $(p=0.000)$ as shown in Table 2 . The results of the Mann-Whitney test also showed that there were significant differences in PDW of each of STEMI group, NSTEMI group, and UAP group from the control $(p=0.000)$ as demonstrated in Table 3. As the results of this research, a research conducted by Pervin et al., ${ }^{4}$ showed that there were significant differences in PDW value between ACS patients, and normals ( $p=0.001$ ) with the mean PDW value of 16.23 \pm 2.56 for the ACS patients, and $11.89 \pm 1.42$ for the control ones. ${ }^{4}$ Costa et al., ${ }^{13}$ also argued that there were significant differences in PDW value between 
ACS patients, and controls $(p=0.01) .^{13}$

In also, the results of the Mann-Whitney post hoc test found that there was no significant difference in PDW value between STEMI group, and NSTEMI group ( $p=0.320)$, between STEMI group, and UAP group ( $p=0.980)$, as well as between NSTEMI group, and UAP group ( $p=0.435)$. This may be due to the small number of samples. Besides, the data were taken from the medical record data, so when the routine blood test was exactly performed, calculated from the time of sampling after the admission of those patients to the emergency unit, it was still not known. According to a study conducted by Vagdatli et al., ${ }^{14}$, the blood samples examined at the first, second, thrd, and fourth hours calculated from the time of sampling tend to obtain a decrease in PDW value due to the reduced formation of platelet pseudopodia. ${ }^{14}$

Moreover, the assessment of PDW values in survived ACS patients revealed that the mean PDW value of survivors was $11.6 \pm 2.4$, lower than the mean PDW value of ACS patients who died (11.9 \pm 1.4). However, the results of the Mann-Whitney test indicated that there was no significant difference in PDW values between survived, and dead patients $(p=0.298)$ as illustrated in Table 4 . This statistical insignificance can be caused by the data of ACS patients who were also suffering from other diseases were still used. According to Jindal et al., ${ }^{15}$ PDW values in patients with diabetes mellitus, especially with microvascular complications, are still bias to be used as a prognostic marker of ACS since they commonly have high PDW values. ${ }^{15}$

In also, Table 5 described the correlation of PDW values, and the length of stay of ACS patients. The mean PDW value of ACS patients with the LOS for $\leq 7$ days was $11 \pm 2.2$, while $12.0 \pm 2.6$ for the ACS patients with the LOS for $>7$ days. It indicated that ACS patients with the LOS of $\leq 7$ days had lower average PDW values than those with the LOS of $>7$ days. Nevertheless, the results of the Mann-Whitney test showed that there was no significant difference $(p=0.293)$. This may be due to the small number of samples used in this research. Research conducted by Myung et al., ${ }^{16}$ explained that PDW values of ACS patients who died in hospital are significantly different from PDW values of survivors, but the correlation of PDW, and the length of stay still needs to be analyzed further. ${ }^{16}$ limitations, such as no follow-up of patients to see the advanced prognosis of ACS. This research was also an observational study using medical record data only. Consequently, it was difficult to avoid bias. Besides this, the normal control group had a different age range.

\section{CONCLUSION AND SUGGESTION}

In conclusion, PDW value in ACS patients was higher than in controls. However, PDW value still could not be used to assess the outcome, and the length of stay of ACS patients. As a result, further researches are expected to use a larger number of samples to avoid bias in their results.

\section{REFERENCES}

1. PERKI. Pedoman Tata Laksana Sindrom Koroner Akut. Jakarta, Centra Communications, 2015; 110.

2. WHO. The Top Ten Causes of Death. Journal [serial on the Internet]. 2008 Date [cited 2016 May $25^{\text {th }}$ ]: Available from: http://www.who.int/ mediacentre/factsheets/fs310_2008.pdf.

3. Manchada J, Potekar RM, Badiger S, Tiwari A. The Study of Platelet Indices in Acute Coronary Syndrome. 2015; 02: 1-5.

4. Pervin S, Islam S, Ferdoushi S, Hossain M. Platelet distribution Width is an Early Indicator of Acute Coronary Syndrome, 2013; 9: 1-7.

5. Bhayana A, Joshi D. Is Large Platelet Size a Risk Factor For Acute Coronary Syndrome: A Retrospective Case-Control Study, 2009; 14: 52-5.

6. Kumar A, Cannon C. Acute Coronary Syndrome: Diagnosis and Management 2009; 917-8.

7. Direktorat Bina Farmasi Komunitas dan Klinik Kementerian Kesehatan. Pharmaceutical Care untuk pasien Penyakit Jantung Koroner: Fokus Sindrom Koroner Akut. Jakarta, Bakti Husada Publisher, 2006; 9-14.

8. Timoteo AT, Alves M, Miranda F, Ferreira ML. Predictive Impact on Medium-term Mortality of Hematological Parameters in Acute Coronary Syndrome: Added Value on Top of GRACE Risk Factor European Heart Journal: Acute Cardiovascular Care. 2015; 4: 172-9.

9. Assiri AS, Jamil AM, Mahfouz AA, Mahmoud ZS. Diagnostic Importance of Platelet Parameter in Patient with Acute Coronary Syndrome Admitted to a Tertiary Care Hospital in Southwest Region, Saudi Arabia. 2011; 17-20. 
10. Kurniawan LB, Bahrun U, Rauf D, Arif M. Analisis Trombosit dengan Mortalitas Pasien Infark Miokard Akut selama Perawatan. Cermin Dunia Kedokteran. 2014; 647-9.

11. Gawaz M. The Evolving Science of Atherothrombotic Disease. European Society of Cardiology. 2008; 10: 14-7.

12. Pipliwal PS, Singh G, Ishran R. Mean Platelet Volume, and other Platelet Volume Indices in Patient with Acute Myocardial Infarction: A CaseControl Study. Journal of Dental and Medical Sciences. 2015; 14(11): 35-8.

13. Costa $\mathrm{S}$, Guilherme $\mathrm{C}$. Platelet Indices in Patients with Acute Coronary Syndrome. Journal of Biosciences and Medicines. 2015; 3(11): 71-6.

14. Vagdatli E, Gounari E, Lazaridou E, Katsibourlia E. Platelet Distribution Width: a Simple, Practical, and Specific Marker of Activation of Coagulation. Hipokratia. 2010; 14: 28-32.
15. Jindal S, Gupta S, Gupta R, Kakkar A, Singh H. Platelet Indices in Diabetes Mellitus: Indicator of Diabetic Microvascular Complications. 2011; 2: 86-9.

16. Myung BH, Jang LH, Dong YH. White Blood Cell, Hemoglobin, and Platelet Distribution Width as Short-Term Prognostic Markers in Patient with Acute Myocardial Infarction. J Korean Med Sci. 2014; 29(4): 519-26. 